\title{
THE EFFECT OF EDUCATIONAL INTERVENTION BASED ON THE THEORY OF PLANNED BEHAVIOUR ON CONSUMPTION OF IRON SUPPLEMENT IN HIGH SCHOOL GIRLS
}

\author{
Hossein Ashtarian'1, Behnaz Marzbani², Afshin Almasi ${ }^{3}$, Behjat Marzbani ${ }^{4}$, Mehdi Khezeli $^{5}$, Sara Shahabadi ${ }^{6}$
}

${ }_{1}^{1}$ Associate Professor, Department of Health Education and Health Promotion, School of Health, Kermanshah University of Medical Sciences, Kermanshah, Iran.

2MSc, Students Research Committee, Kermanshah University of Medical Sciences, Kermanshah, Iran.

${ }_{3}^{3}$ Assistant Professor, Research Center for Environmental Determinants of Health, Kermanshah University of Medical Sciences, Kermanshah, Iran.

${ }^{4}$ MSc, Health Education and Promotion Group, Vice Chancellor for Health Affairs, Kermanshah University of Medical Sciences, Kermanshah, Iran.

${ }_{5}^{5} \mathrm{Ph}$, Research Center for Environmental Determinants of Health, Kermanshah University of Medical Sciences, Kermanshah, Iran. ${ }^{6} \mathrm{PhD}$, Health Education and Promotion Group, Vice Chancellor for Health Affairs, Kermanshah University of Medical Sciences, Kermanshah, Iran.

\section{BACKGROUND}

\section{ABSTRACT}

Iron deficiency anaemia is one of the most common nutritional problems in Iran, especially in women and adolescent girls. Iron supplementation is the most cost-effective and most common strategy used by developed countries to control the iron deficiency.

The purpose of this study was to investigate the effect of education based on the theory of planned behaviour on consumption of iron supplement in secondary school girls in Kermanshah, 2017.

\section{MATERIALS AND METHODS}

This quasi-experimental study was carried out with 174 students, girls of first grade of secondary high school from Kermanshah city. The subjects were selected by multistage random sampling method. The students were divided into three groups including student $(n=58)$, student with mother $(n=58)$ and one control group $(n=58)$. A researcher-made questionnaire based on the theory of planned behaviour was used to collect the data. Participants completed self-report questionnaire on demographic variables and theoretical constructs. Then based on the initial results, the educational content was developed. The data were collected immediately and one month after the implementation of the training program it was analysed with SPSS 20 software using Kruskal-Wallis, Mann-Whitney and Friedman tests.

\section{RESULTS}

The mean scores of knowledge, attitude, perceived behavioural control, subjective norms, intention and behaviour of iron supplementation immediately and one month after intervention was significantly increased in intervention groups (P < 0.05$)$. However, there was no significant difference between the two intervention groups, although there was a better situation in the intervention group with the mother.

\section{CONCLUSION}

The results of the research show that educational intervention based on the theory of planned behaviour can affect all the structures of the theory and ultimately change the behaviour of the consumption of iron tablets in students.

\section{KEY WORDS}

Anaemia, Iron Supplementation, Iron Tablet, Theory of Planned Behaviour.

HOW TO CITE THIS ARTICLE: Ashtarian H, Marzbani B, Almasi A, et al. The effect of educational intervention based on the theory of planned behaviour on consumption of iron supplement in high school girls. J. Evolution Med. Dent. Sci. 2018;7(39):4291-4298, DOI: $10.14260 /$ jemds/2018/957

\section{BACKGROUND}

These days Iron deficiency is one of the most common diseases in the world affecting the development of physical, mental and behavioural disorders. ${ }^{(1,2)}$ According to the World

'Financial or Other Competing Interest': Dr. Marzbani Reports Grants from Kermanshah University of Medical Sciences, outside the submitted work.

Submission 06-08-2018, Peer Review 09-09-2018,

Acceptance 15-09-2018, Published 24-09-2018.

Corresponding Author:

Behnaz Marzbani,

Students Research Committee,

Kermanshah University of Medical Sciences,

Kermanshah, Iran.

E-mail: marzbanibehnaz@gmail.com

DOI: $10.14260 /$ jemds $/ 2018 / 957$
Health Organization (WHO), one in four people in the world are suffering from an iron deficiency anaemia. $(3,4)$ The results of studies show that the prevalence of anaemia is higher in women than men.(5) The results of a study on girls aged between 14 and 18 years old in Mashhad in 2013 showed that $20.7 \%$ of girls had iron deficiency anaemia.(6) The results of a study on a 14 - 20 year old high school girls in Kermanshah showed that $21.4 \%$ of the girls had anaemia and $57.3 \%$ had reported iron deficiency.(7) Another study in Kermanshah also reported that 44 percent of the students suffered from iron deficiency.(8)

Therefore, high prevalence of iron deficiency anaemia, particularly in adolescent girls need more attention. It affects the mental and emotional development of adolescents, and may also affect their auditory and visual performances. ${ }^{(9)}$ People with iron deficiency always feel tired, not interested in doing work and their productivity is reduced.(10) The amount 
of learning and academic achievement in adolescents with anaemia is lower than that of healthy people.(11) Students with iron deficiency anaemia have problems such as weakness in doing homework, reducing physical and sensory abilities, reducing attention and concentration, reducing learning ability and memory capacity.(12) Therefore, to prevent these risks, adolescent girls are an important target group to receive education for the prevention of iron deficiency anaemia, especially before child bearing.(13)

Anaemia caused by iron deficiency is a multifactorial disorder, the most important causes of which are the increased need for Iron, inadequate intake, lack of iron absorption and transport and iron deficiency.(14) The WHO has proposed several strategies to prevent and control iron deficiency including food enrichment, dietary diversity and iron supplementation.(15) In Iran, the program for improving the health of female students through nutrition education and iron supplementation (Iron tablets distribution) has been implemented in all high schools and secondary schools since 2006. According to the Ministry of Health, distribution of Ferrous Sulfate tablets per week is done for the 16 consecutive weeks during the school year.(16)

An assessment of the implementation of this project in Tabriz shows that around $48 \%$ of students refuse to take iron tablets. In addition, students receive limited education in this regard, and despite the emphasis on parenting education for the accurate implementation of the program, evidence suggests that only $15 \%$ of the parents are trained in this regard.(17) Therefore, there is a need for raising of learners and parents through appropriate training.

To implement an effective intervention using an appropriate model for behaviour change is important, such as the theory of planned behaviour which has been used in many studies including in the studies related to the use of multivitamins and family planning.(18) This theory provides a framework for studying attitudes through behaviours which relies on a number of structures including behaviour, behavioural intention, attitude, subjective norms and perceived behavioural control. The "behaviour" refers to the way a person acts. "Behavioural intention" refers to the individual's decision to adopt a behaviour. "Attitude towards Behaviour" takes into account the degree of utility or inappropriateness of a behaviour. "Subjective Norms" also assumes that most important people how to think about the intended behaviour and the effect of their views on the individual. "Perceived behavioural control" refers to the extent to which a behaviour is under the control.(19,20) Given the high prevalence and prevalence of anaemia and the need for education in girls, this study was aimed to examine the effect of an education based on the theory of planned behaviour on iron deficiency in second grade female students in Kermanshah.

\section{MATERIALS AND METHODS}

The present study is a quasi-experimental study, which was conducted on 174 first-grade female students of secondary high school. In order to sampling, in the first step we conducted the Pilot study on 20 students to measure the behaviour. Based on the results and the following assumption, the sample size in each group was calculated using the appropriate formula in which $\sigma=4.5, d=3, \alpha=0.05$, $\beta=.20$. Considering that the groups compared in this study were more than two groups, the sample size was corrected using Formula 2 Then, with the exclusion probability of some participants from the study, $20 \%$ were added to each group. The final sample size in each group was 60 students. Sample size was similar to the studies.(10,21,22) Two participants in control group due to incomplete questionnaire and four in the intervention groups because they did not meet the inclusion criteria were excluded from the study and finally 58 students in each group participated in the study.

$$
\text { Formula 1: } n=\frac{2 \sigma^{2}\left(Z_{1-\alpha / 2}+Z_{1-\beta}\right)^{2}}{d^{2}}
$$

Formula 2: $n=\sqrt{K} n$

In this study, students were divided into two groups of intervention and one control group. The first intervention group consisted of 58 students, the second intervention group was 58 students with their mothers and the control group consisted of 58 students. The inclusion criteria included for the mother having at least reading and writing skills, and for students being a girl and studying in the first grade of high school in the moderate economic zones of Kermanshah. Students were selected from schools of moderate economic areas to be similar in terms of facilities and socioeconomic status, and to reduce the bias in the study.(23) Exclusion criteria included having thalassemia, the medical prohibition of iron supplementation, the lack of willingness to participate in the study and absent in one of the training sessions. In this research, multistage sampling method was used. After coordination with the authorities of the three education districts of Kermanshah, two schools from each district and totally 6 schools were selected using simple random method. Then, considering that the schools were selected from the middle socio-economic areas of Kermanshah city, Flip the coin method was used for random allocation to allocate schools to the control and intervention groups in each district. Thus, in each area, a school was assigned as an intervention group and a school as a control group. In intervention schools also using the simple random method one class was randomly selected as an only student intervention group, and another class was selected as a student with the mother intervention group.

Data gathering tool was a three-part researcher-made questionnaire consisting of 48 questions. The first part of the questionnaire was demographic questions. The second part included 15 questions in four options format for assessing participants' awareness about the subject study. In order to assess questions of knowledge, each correct answer was scored by one, and each wrong score was scored zero. The third part also included 23 questions related to the structures of the theory of planned behaviour including attitude, perceived behavioural control, subjective norms, behavioural intention and behaviour. The questions in this section were designed with Likert scale five options. The Attitude Section had 5 questions, for example: "I think that taking iron tablets is very important." The perceived behavioural control was examined with 5 questions, for example: "Eating iron tablets is easy for me once a week." The subjective norms were measured with 6 questions, for example: "My mother encourages me to take iron tablets." The behavioural intention had three questions: "I intend to eat iron tablets regularly." Finally, the behaviour was 
evaluated with 4 questions, for example: "I currently consume one tablet of iron per week."

The validity of the questionnaire was assessed by content validity method, so that the questionnaire was prepared using previous researches and valid sources. $(18,24)$ Then the questionnaire was sent to 12 health education as well as nutrition specialists and based on their feedback corrections were made on the questionnaire. Ultimately, after resolving some of the bugs and ambiguities, the validity of the questionnaire was confirmed by $\mathrm{CVR}=0.77$ and $\mathrm{CVI}=0.95$. To determine the reliability, after a pilot study on 20 students Cronbach's alpha coefficient test was used. The Cronbach's alpha coefficient of the total TPB tool was $(\alpha=0.79)$ and for its structures was as follows: intention $(\alpha=0.84)$, attitude $(\alpha=$ $0.83)$, behaviour $(a=0.8)$, perceived behavioural control $(\alpha=$ 0.76 ) and subjective norms ( $\alpha=0.73)$. Also Cronbach's alpha coefficient for knowledge was $(\alpha=0.72)$. The questionnaires were completed by students using self-report method before the intervention, immediately after the intervention and one month after the intervention.

\section{Intervention}

After data collection in intervention and control groups, educational intervention was started based on pre-test results of theory of planned behaviour for intervention groups. This intervention was carried out by holding three 90-minute training sessions for students in two intervention groups included only student and student with a mother. A 30-minute training session was conducted for teachers and trainers in both intervention groups. A 45-minute session was also held for the mothers of the student in intervention group of students along with the mother. At the first session, the issues on anaemia, iron absorption and iron deficiency disorders was presented. In order to establish the correct attitude, overcoming negative attitudes and strengthening the positive attitude toward iron pill consumption, educations were presented using lecture, inquiry and group discussion. At the end of the session, a short video on how to absorb iron in the digestive tract was displayed and asked people to note the important points of the film and discuss it in the end. The goal of the meeting was to raise awareness, attract attention, sensitise and influence student attitudes. In the second session, the ways of prevention of iron deficiency anaemia, consumption of iron supplementation, food sources and subjective norms regarding iron supplementation was provided. In the context of influencing subjective norms, a brochure on prevention of anaemia in girls using iron supplement was delivered to students. The third session was conducted for the purpose of influencing the perceived behavioural control, intention and behaviour for 90 minutes. In order to influence the perceived behaviour control, discussion was focused on factors that facilitated behaviour, incentives and reduced deterrent factors. Also, methods such as breaking behaviour into small steps, encouraging and reinforcing behaviour were used to increase self-efficacy.(25) In the brochure in addition to providing educational materials, students were asked to write barriers and facilitators to discuss in the second session. In the brochure to enhance self-efficacy, an iron supplementation table was designed. Students were asked if taking an iron supplement (One pill per week to the end of the iron aid program) mark positive on the table and if the iron tablet was not used mark negative. Then at the second and third sessions, the table was examined by the educator and the students who took the pill were encouraged by friends and coach. Also, in order to make a reminder to eat iron tablets by students, an educational tract with the text "I Eat an Iron pill weekly" was installed on the class wall. In the following, the difficulty and comfort of use of iron tablets were discussed. In addition, the role of a desirable behavioural pattern was used, so that a student who regularly took the iron pill was invited to speak about her experience with the participants. In order to strengthen the subjective norms, in the interval between the first and second training sessions, an educational session was conducted for teachers and trainers about the importance and role of iron tablets in the prevention of anaemia. Also, the students were encouraged to take supplements and they were asked to talk about the importance of taking iron tablets during the intervention in the first 10 minutes of the classroom. In each class, three students were trained to train peers and encouraged their classmates to take iron supplementation. In teaching mothers in the intervention group of the student with the mother, the importance and role of iron supplementation in the health of students and their encouragement to use iron tablets were emphasised and at the end of the session the educational brochure in this regard was given to the mothers.

This research was approved by Ethical Committee of Kermanshah University of Medical Sciences. At the beginning of the study, informed consent form was obtained from the participants. The purpose of the study and the voluntary participation in the study were explained to those eligible to participate in the study. The individuals were assured of the lack of unjustified use of information and the confidentiality of information. Data analysis was done using SPSS-20 software. We used Kolmogorov-Smirnov to assess the normality of data and results showed that data had nonnormal distribution. So we used the suitable non-parametric tests including Chi-square, Kruskal-Wallis, Mann-Whitney, Friedman and Wilcoxon tests. The significance level of the tests was considered to be 0.05 .

\section{RESULTS}

In this study, a total of 174 students including 116 in the two intervention groups and 58 students in the control group participated. Table 1 showed that there was a significant difference between the mean score of the studied variables in each educational intervention group in the three measurement periods $(p<0.05)$, while the control group did not show significant difference between the three periods ( $p>0.05$ ). Based on the Wilcoxon test showed in Table 1, the mean and standard deviation of the variables of the theory of planned behaviour and awareness at the time intervals including before and after the intervention, immediately after and one month after the intervention, and before with one month after the intervention in the intervention groups of the student and the student with the mother was significantly increased $(\mathrm{p}<0.001)$.

As shown in Table 2, the comparison of relative changes of variables based on Kruskal-Wallis showed that the percentage of relative changes in knowledge and the constructs of the planned behaviour theory after intervention with before and one month after intervention in the three groups was significantly different. Status in the intervention group of the student with the mother was 
better, indicating that the educational intervention was more effective in this group compared to the only student's intervention group.

Also the Mann-Whitney test showed there was no significant difference in knowledge and all variables of the theory of planned behaviour between the intervention group of the only student and the student with the mother at before with immediately after the intervention and before with one month after the intervention. However, there was a better situation in the intervention group with the mother compared to the only student intervention group (Table 3 ).

\begin{tabular}{|c|c|c|c|c|c|c|c|c|}
\hline \multirow[b]{2}{*}{ Variables } & \multirow[b]{2}{*}{ Groups } & \multicolumn{3}{|c|}{ Time Interval from Intervention } & \multirow[b]{2}{*}{ P-value * } & \multirow[b]{2}{*}{ P-value A } & \multirow[b]{2}{*}{ P-value B } & \multirow[b]{2}{*}{ P-value C } \\
\hline & & $\begin{array}{c}\text { Before } \\
\text { Mean } \pm \text { SD }\end{array}$ & $\begin{array}{c}\text { After } \\
\text { Mean } \pm S D\end{array}$ & $\begin{array}{c}\text { One Month } \\
\text { After } \\
\text { Mean } \pm \text { SD }\end{array}$ & & & & \\
\hline \multirow{3}{*}{ Awareness } & Only students & $9.93 \pm 2.05$ & $13.67 \pm 1.47$ & $12.79 \pm 1.97$ & $<0.05$ & $<0.001$ & $=0.004$ & $<0.001$ \\
\hline & $\begin{array}{l}\text { Students with } \\
\text { mothers }\end{array}$ & $10.08 \pm 2.15$ & $14.05 \pm .88$ & $13.22 \pm 1.33$ & $<0.05$ & $<0.001$ & $<0.001$ & $<0.001$ \\
\hline & Control & $9.82 \pm 1.93$ & $10.17 \pm 1.89$ & $10.0 \pm 1.76$ & 0.218 & & & \\
\hline \multirow{3}{*}{ Attitude } & Only students & $18.53 \pm 3.27$ & $22.44 \pm 2.85$ & $21.87 \pm 2.91$ & $<0.05$ & $<0.001$ & $=0.122$ & $<0.001$ \\
\hline & $\begin{array}{l}\text { Students with } \\
\text { mothers }\end{array}$ & $18.60 \pm 3.35$ & $23.65 \pm 1.87$ & $23.10 \pm 2.19$ & $<0.05$ & $<0.001$ & $=0.084$ & $<0.001$ \\
\hline & Control & $19.08 \pm 3.91$ & $20.10 \pm 3.44$ & $19.58 \pm 3.35$ & 0.125 & & & \\
\hline \multirow{3}{*}{$\begin{array}{l}\text { Subjective } \\
\text { Norms }\end{array}$} & Only students & $17.87 \pm 3.93$ & $24.62 \pm 3.60$ & $22.65 \pm 4.38$ & $<0.05$ & $<0.001$ & $<0.001$ & $<0.001$ \\
\hline & $\begin{array}{c}\text { Students with } \\
\text { mothers }\end{array}$ & $17.17 \pm 4.12$ & $26.56 \pm 3.45$ & $23.39 \pm 4.11$ & $<0.05$ & $<0.001$ & $<0.001$ & $<0.001$ \\
\hline & Control & $19.0 \pm 3.83$ & $18.72 \pm 4.43$ & $19.06 \pm 3.74$ & 0.335 & & & \\
\hline \multirow{3}{*}{$\begin{array}{l}\text { Perceived } \\
\text { Behavioural } \\
\text { Control }\end{array}$} & Only students & $14.22 \pm 3.14$ & $20.18 \pm 3.08$ & $18.67 \pm 2.92$ & $<0.05$ & $<0.001$ & $<0.001$ & $<0.001$ \\
\hline & $\begin{array}{c}\text { Students with } \\
\text { mothers }\end{array}$ & $14.65 \pm 3.64$ & $22.44 \pm 2.86$ & $20.79 \pm 3.17$ & $<0.05$ & $<0.001$ & $<0.001$ & $<0.001$ \\
\hline & Control & $15.58 \pm 3.72$ & $15.15 \pm 2.62$ & $15.52 \pm 2.26$ & 0.726 & & & \\
\hline \multirow{3}{*}{$\begin{array}{l}\text { Behavioural } \\
\text { Intention }\end{array}$} & Only students & $9.77 \pm 3.33$ & $13.70 \pm 1.65$ & $12.44 \pm 2.53$ & $<0.05$ & $<0.001$ & $<0.001$ & $<0.001$ \\
\hline & $\begin{array}{c}\text { Students with } \\
\text { mothers }\end{array}$ & $9.96 \pm 3.51$ & $14.18 \pm 1.62$ & $13.43 \pm 2.06$ & $<0.05$ & $<0.001$ & $<0.001$ & $<0.001$ \\
\hline & Control & $9.62 \pm 3.53$ & $10.03 \pm 3.44$ & $9.87 \pm 3.39$ & 0.139 & & & \\
\hline \multirow{3}{*}{ Behaviour } & Only students & $9.70 \pm 3.67$ & $17.12 \pm 2.87$ & $15.41 \pm 3.58$ & $<0.05$ & $<0.001$ & $<0.001$ & $<0.001$ \\
\hline & $\begin{array}{l}\text { Students with } \\
\text { mothers }\end{array}$ & $10.13 \pm 4.30$ & $18.5 \pm 2.5$ & $17.43 \pm 2.98$ & $<0.05$ & $<0.001$ & $<0.001$ & $<0.001$ \\
\hline & Control & $10.27 \pm 4.20$ & $10.98 \pm 4.39$ & $10.88 \pm 3.90$ & 0.351 & & & \\
\hline
\end{tabular}

P-value*: Friedman test.

P-value-A: Wilcoxon test for comparison before and after intervention.

P-value-B: Wilcoxon test comparison after and one month after intervention.

P-value-C: Wilcoxon test comparison before and one month after intervention.

\begin{tabular}{|c|c|c|c|}
\hline \multirow[b]{2}{*}{ Variables } & \multirow[b]{2}{*}{ Groups } & \multicolumn{2}{|c|}{ Time Interval of Analysis } \\
\hline & & $\begin{array}{l}\text { Before vs. After } \\
\text { (Mean } \pm \text { SD) }\end{array}$ & $\begin{array}{c}\text { Before vs. One Month } \\
\text { After (Mean } \pm \text { SD) }\end{array}$ \\
\hline \multirow{4}{*}{ Awareness } & Only students & $44.46 \pm 38.45$ & $34.66 \pm 37.05$ \\
\hline & Students with mothers & $46.05 \pm 34.74$ & $36.61 \pm 30.55$ \\
\hline & Control & $5.12 \pm 17.72$ & $2.56 \pm 8.86$ \\
\hline & P-value (Kruskal-Wallis) & $\mathrm{P}<0 / 001$ & $\mathrm{P}<0 / 001$ \\
\hline \multirow{4}{*}{ Attitude } & Only students & $24.22 \pm 23.72$ & $20.58 \pm 22.07$ \\
\hline & Students with mothers & $31.38 \pm 27.73$ & $28.24 \pm 27.60$ \\
\hline & Control & $8.29 \pm 25.21$ & $4.11 \pm 12.63$ \\
\hline & P-value (Kruskal-Wallis) & $\mathrm{P}<0 / 001$ & $\mathrm{P}<0 / 001$ \\
\hline \multirow{4}{*}{ Subjective Norms } & Only students & $44.77 \pm 41.09$ & $31.20 \pm 34.13$ \\
\hline & Students with mothers & $64.86 \pm 51.98$ & $45.25 \pm 50.46$ \\
\hline & Control & $2.69 \pm 19.03$ & $1.43 \pm 16.79$ \\
\hline & P-value (Kruskal-Wallis) & $\mathrm{P}<0 / 001$ & $\mathrm{P}<0 / 001$ \\
\hline \multirow{4}{*}{ Perceived Behavioural Control } & Only students & $49.56 \pm 43.33$ & $38.76 \pm 43.23$ \\
\hline & Students with mothers & $64.82 \pm 61.44$ & $50.48 \pm 45.16$ \\
\hline & Control & $.59 \pm 21.17$ & $.21 \pm 10.75$ \\
\hline & P-value (Kruskal-Wallis) & $\mathrm{P}<0 / 001$ & $\mathrm{P}<0 / 001$ \\
\hline \multirow{3}{*}{ Behavioural Intention } & Only students & $63.60 \pm 84.40$ & $46.07 \pm 74.10$ \\
\hline & Students with mothers & $76.30 \pm 112.39$ & $61.45 \pm 93.00$ \\
\hline & Control & $6.82 \pm 20.44$ & $4.02 \pm 11.09$ \\
\hline
\end{tabular}




\begin{tabular}{|c|c|c|c|}
\hline & P-value (Kruskal-Wallis) & $\mathrm{P}<0 / 001$ & $\mathrm{P}<0 / 001$ \\
\hline \multirow{3}{*}{ Behaviour } & Only students & $107.07 \pm 102.85$ & $86.14 \pm 105.01$ \\
\cline { 2 - 4 } & Students with mothers & $121.19 \pm 112.92$ & $106.7 \pm 102.65$ \\
\cline { 2 - 4 } & Control & $15.22 \pm 61.48$ & $11.32 \pm 35.47$ \\
\cline { 2 - 4 } & P-value (Kruskal-Wallis) & $\mathrm{P}<0 / 001$ & $\mathrm{P}<0 / 001$ \\
\hline \multicolumn{2}{|c|}{ Table 2. Comparison of Relative Changes in Knowledge and Constructs of Theory of Planned Behaviour in Three Groups } \\
\hline
\end{tabular}

\begin{tabular}{|c|c|c|c|}
\hline \multirow[b]{2}{*}{ Variables } & \multirow[b]{2}{*}{ Groups } & \multicolumn{2}{|c|}{ Time Interval of Analysis } \\
\hline & & $\begin{array}{l}\text { Before vs. After } \\
\text { (Mean } \pm \text { SD) }\end{array}$ & $\begin{array}{c}\text { Before vs. One Month } \\
\text { After (Mean } \pm \text { SD) }\end{array}$ \\
\hline \multirow{3}{*}{ Awareness } & Only students & $44.46 \pm 38.45$ & $34.66 \pm 37.05$ \\
\hline & Students with mothers & $46.05 \pm 34.74$ & $36.61 \pm 30.55$ \\
\hline & P-value (Mann-Whitney) & $\mathrm{P}<0 / 99$ & $\mathrm{P}<0 / 99$ \\
\hline \multirow{3}{*}{ Attitude } & Only students & $24.22 \pm 23.72$ & $20.58 \pm 22.07$ \\
\hline & Students with mothers & $31.38 \pm 27.73$ & $28.24 \pm 27.60$ \\
\hline & P-value (Mann-Whitney) & $\mathrm{P}<0 / 053$ & $\mathrm{P}<0 / 495$ \\
\hline \multirow{3}{*}{ Subjective Norms } & Only students & $44.77 \pm 41.09$ & $31.20 \pm 34.13$ \\
\hline & Students with mothers & $64.86 \pm 51.98$ & $45.25 \pm 50.46$ \\
\hline & P-value (Mann-Whitney) & $\mathrm{P}<0 / 12$ & $\mathrm{P}<0 / 492$ \\
\hline \multirow{3}{*}{ Perceived Behavioural Control } & Only students & $49.56 \pm 43.33$ & $38.76 \pm 43.23$ \\
\hline & Students with mothers & $64.82 \pm 61.44$ & $50.48 \pm 45.16$ \\
\hline & P-value (Mann-Whitney) & $\mathrm{P}<0 / 517$ & $\mathrm{P}<0 / 336$ \\
\hline \multirow{3}{*}{ Behavioural Intention } & Only students & $63.60 \pm 84.40$ & $46.07 \pm 74.10$ \\
\hline & Students with mothers & $76.30 \pm 112.39$ & $61.45 \pm 93.00$ \\
\hline & P-value (Mann-Whitney) & $\mathrm{P}<0 / 99$ & $\mathrm{P}<0 / 783$ \\
\hline \multirow{3}{*}{ Behaviour } & Only students & $107.07 \pm 102.85$ & $86.14 \pm 105.01$ \\
\hline & Students with mothers & $121.19 \pm 112.92$ & $106.7 \pm 102.65$ \\
\hline & P-value (Mann-Whitney) & $\mathrm{P}<0 / 99$ & $\mathrm{P}<0 / 538$ \\
\hline
\end{tabular}

Table 3. Comparison of Relative Changes in Knowledge and Constructs of Theory of Planned Behaviour in Two Intervention Groups

\section{DISCUSSION}

The aim of this study was to determine the effect of educational intervention based on the theory of planned behaviour on the consumption of iron tablets in secondary school students in Kermanshah. The findings of the study showed that iron supplementation in intervention groups significantly increased. In every effort made to create a healthy behaviour, having information and awareness is the first key element.(20) The findings of this study showed that the mean score of knowledge in the intervention groups of students and students with the mother after and one month after the intervention was significantly increased, while there was no significant difference in the control group. Heidarnia and colleagues showed that the average score of awareness increased in a group of teenage girls who received nutritional education for 3 months.(26) Other studies(22,27-30) also indicated that the educational intervention had a positive effect on increasing students' awareness about iron deficiency anaemia, which are consistent with the results of this study. In another study, educational intervention did not have significant effect on increasing students' knowledge about iron deficiency anaemia in the intervention group after the training. One of the probable reasons for insignificant result of the mentioned study was a small number and short time of sessions. (31)

Attitude is a positive or negative evaluation of a behaviour.(20) In this study, the mean score of attitude in the intervention groups including the only students and the students with the mothers were significantly higher than the control group immediately and one month after education, indicating the effect of educational intervention on the attitude of the students. This finding is consistent with similar studies that showed the education effectively influenced students' attitudes towards iron supplementation, $(10,18,21,24,30,32)$ but some studies also showed that after educational intervention students' attitude did not change significantly. $(31,33)$ In studies with positive results, the use of interactive training methods could have created positive attitudes in the minds of students. In the present study the use of educational methods such as inquiry, brainstorming, group discussion and role playing could cause significant changes in the attitudes of students in the intervention group.

In the present study, the results indicated that the educational program had an impact on the subjective norms in the intervention groups compared to the control group immediately and one month after the intervention. However, there was no significant difference between the two intervention groups, but in the group of student-with-themother was better. Subjective norms from the perspective of a person are a kind of social pressure by the important or valuable individuals that cause a healthy behaviour or failure to do so. ${ }^{(20)}$ The findings of this study are in line with some similar studies.(33,34) However, one study showed that education based on planned behavioural theory did not show significant increase in subjective norms after the intervention in both groups. (18) In contrast in the study of Ahmadi et al,(35) mean scores of subjective norms of the case group decreased significantly after intervention, which is inconsistent with this study. Also, in the study of Mohammadi Mansesh et al, the mean score of subjective norms in the intervention group after the intervention was not changed. The differences noted in various studies indicate that in order to increase the score of subjective norms, a more accurate analysis of normative sources around individuals should be performed.(36) In the present study, by educating important people from the 
viewpoint of students, the normative beliefs of students have been changed to increase the use of iron tablets. The subjective norms for the students in this study were in three areas of mothers, teachers and classmates that intervened for each of these norms. Also, using the behavioural role model, students who used regular iron tablets expressed their experiences and conducted discussion on strategies for taking iron tablets in students.

Perceived Behavioural Control is the degree to which an individual's feelings about whether conducting or not to conduct a behaviour is under his/ her control.(20) The average score of perceived behavioural control in intervention groups was higher than control group immediately and one month after the intervention, which was statistically significant and showed an effective education. The results of this study is consistent with similar studies.(10,21,36,37) According to the Researcher's experiences during the study, it seems that if students believe that they do not have opportunities to eat iron tablets, the probability of performing the desired activity is less likely, even if students have a positive attitude toward behaviour or if they believe that other important people do not confirm this behaviour. Among the facilitators that promote the consumption of iron tablets in students, we can mention to the training, the distribution of water and disposable glasses at a time and the allocation of proper time in the classroom to eat iron tablets. The use of the brochure (Table of iron intake) reminded students to the behaviour of iron tablets. Among the barriers to iron tablets intake, we can mention to lack of training on iron supplementation, lack of water during the distribution of iron tablets, forgetfulness, incuriosity, bad taste and intolerance to iron tablets. According to the results of perceived barriers, necessary interventions were performed step-by-step to remove all barriers.

Behavioural intention refers to the individual's intention to perform a particular behaviour.(20) The results showed that the mean score of behavioural intention was significantly higher immediately and one month after the intervention in the intervention groups, but there was no significant difference in the control group. The results of this study is consistent with similar studies $(28,38)$ regarding the effect of education to change the nutritional behaviour of students on behavioural intent. In another study education was effective on the students' intention to use multivitamin tablets, which is consistent with the present study. (34) A study found that the intention to use supplements has the most predictive power to use in food supplements.(39) Also, in the other study, the intervention was effective on the intention of pregnant mothers regarding consumption of iron supplementation, which is consistent with the present study.(18)

The purpose of health education in health sciences is to change health behaviours. Behaviour is a combination of knowledge and tendencies with other factors and in different proportions. Behaviour is affected by accidental factors, practical possibilities, current issues and many other factors. (20) The results of this study also showed that the consumption of iron supplementation by students increased after intervention, but there was no statistically significant difference between the two intervention groups. Based on similar studies, education has had a significant impact on students' performance in taking iron tablets. $(10,18,23,40)$ Other studies also confirmed that educational interventions improve and improve the preventive behaviours of iron deficiency anaemia in girls. $(38,41,42)$ In one study, there was no significant difference between the two groups after the intervention, which did not conform to the present study.(31)

One of the strengths of the present study is to divide intervention groups into a student group and a student group with a mother. Another important point of this study was the design of a table on tablet consumption in a distributed brochure among students, which should be marked with tablet intake and could increase the chance of increasing selfefficacy.

One of the limitations of this study was the short-term evaluation period due to the time constraints on the implementation of the school iron-aid program, which is suggested to be considered in future studies in order to longer follow-up period. Other limitation of the study was holding just one training session for mothers. In this study, the role of teacher as a role model was not investigated. Despite the important role of the teacher in transferring the concepts of health education to students, this potential is neglected in nutrition education studies.(43) Therefore, it is suggested that in future studies, active participation of teachers in health education be used by students.

\section{CONCLUSION}

Based on the results of the study, the mean score of knowledge and constructs of the theory of planned behaviour in the intervention groups was significantly higher than the control group immediately and one month later, indicating the effectiveness of the educational intervention. The results of this study showed that iron supplementation can be promoted in students. Based on the theory of planned behaviour, when students have adequate knowledge and positive attitude towards taking iron tablets, and they feel that taking iron tablets is controlled by them in terms of environmental factors such as facilities and barriers, they intend to take the iron tablets.

\section{ACKNOWLEDGEMENTS}

We would like to thank the Kermanshah University of Medical Sciences for financing this project (Grant No.: KUMS.REC 1395.600).

\section{REFERENCES}

[1] Akarsu S, Kilic M, Yilmaz E, et al. Frequency of hypoferritinemia, iron deficiency and iron deficiency anemia in outpatients. Acta Haematologica 2006;116(1):46-50.

[2] Raymond J, Mahan L, Escott-Stump S. Krause's food \& nutrition therapy. Philadelphia, PA: Saunders Elsevier 2008.

[3] De Benoist B, McLean E, Egli I, et al. Worldwide prevalence of anaemia 1993-2005: WHO global database on anaemia. 2008.

[4] Kassebaum NJ, Jasrasaria R, Naghavi M, et al. A systematic analysis of global anemia burden from 1990 to 2010. Blood 2014;123(5):615-24. 
[5] Shakouri S, Sharifirad G, Golshiri P, et al. Effect of health education program base on PRECEDE Model in controlling iron-deficiency anemia among high school girl students in Talesh. J Arak Uni Med Sci 2009;12(3):47-56.

[6] Abrishami F, Golshan A. Frequency of iron deficiency anemia in girls studying in Mashhad high schools. Iran J Ped Hematol Oncol 2013;3(4):143-8.

[7] Akramipour R, Rezaei M, Rahimi Z. Prevalence of iron deficiency anemia among adolescent schoolgirls from Kermanshah, Western Iran. Hematology 2008;13(6):352-5.

[8] Pasdar Y, Heydarpour F, Darbandi M, et al. Anemia, iron deficiency and affecting factors on it in between Girls' students of Kermanshah University of Medical Sciences. J Clin Res Paramed Sci 2015;4(3):213-22.

[9] Killip S, Bennett JM, Chambers MD. Iron deficiency anemia. American family physician. Am Fam Physician 2007;75(5):671-8.

[10] Shakouri S, Sharifirad G, Golshiri P, et al. Effect of health education program base on PRECEDE Model in controlling iron-deficiency anemia among high school girl students in Talesh. J Arak Uni Med Sci 2009;12(3):47-56.

[11] Abdollahy Z. Survey Iron deficiency anemia in girls 1418 years old high school at Tehran: M. Sc thesis, Tehran Medical University, 1992.

[12] Soleimani N, Abbaszadeh N. Relationship between anaemia, caused from the iron deficiency and academic achievement among third grade high school female students. Procedia-Social and Behavioral Sciences 2011;29:1877-84.

[13] Falahi E, Rashidi M, Ebrahimzadeh F, et al. Effect of nutritional education on iron-deficiency anemia in high schools girls. Journal of Shahrekord University of Medical Sciences 2010;12(1):37-45.

[14] Mozaffari-Khosravi H, Shadkam MN, Naghiaee Y. Prevalence of iron deficiency and iron deficiency anemia in high-school girl students of Yazd. Journal of Shahid Sadoughi University of Medical Sciences 2009;17(3):135-41.

[15] World Health Organization. Iron deficiency anaemia: assessment, prevention and control: a guide for programme managers. Geneva, WHO, 2001.

[16] Shafai SF, Charandabi MS, Mamaghani EM, et al. Educating female adolescent about iron deficiency and taking iron supplements and its influence on their peers. 2013;23(1):223-33.

[17] Kheirouri S, Alizadeh M. Process evaluation of a national school-based iron supplementation program for adolescent girls in Iran. BMC Public Health 2014;14(1):959.

[18] Jalambadani Z, Zadeh DS, Hoseini M, et al. The effect of education for iron consumption based on the theory of planned behavior in pregnant women in Mashhad. Journal of Clinical Nursing and Midwifery 2015;4(3):59-68.

[19] Sharma M. Theoretical foundations of health education and health promotion. Jones \& Bartlett Publishers 2016.
[20] Ajzen I. The theory of planned behavior: reactions and reflections. Psychol Health 2011;26(9):1113-27.

[21] Shahnazi H, Motahareh TI, Samira A, et al. Impact of education on precede model on knowledge, attitude and behavior of grade two guidace school regarding Iron Deficiency Anemia (IDA) in Isfahan, Iran. Health System Research 2012;8(5):773-81.

[22] Sadeghifar J, Jafari H, Pourmohammad A, et al. Educational intervention on knowledge, attitude and practice (KAP) on girl students (high school) in Baneh city about iron deficiency anemia in 2008-2009. Jundishapur Journal of Health Sciences 2012;4(2):3946.

[23] Khorasani EC, Peyman N, Moghzi M. Application of the theory of planned behavior to predict low-nutrient junk food consumption among male students. J Health Sci Technol 2017;1(2):75-9.

[24] Pawlak R, Brown D, Meyer MK, et al. Theory of planned behavior and multivitamin supplement use in Caucasian college females. The Journal of Primary Prevention 2008;29(1):57-71.

[25] Rajati F, Mostafavi F, Sharifirad G, et al. A theory-based exercise intervention in patients with heart failure: $\mathrm{A}$ protocol for randomized, controlled trial. J Res Med Sci 2013;18(8):659-67.

[26] Heidarnia A, Amiri P, Parvyn M, et al. Design and evaluation of educational programs to reduce iron deficiency anemia in health behaviors in girls with dysmenorrhea. Journal of American Science 2011;7(1):431-8.

[27] Fathizadeh S, Shojaeizadeh D, Mahmoodi M, et al. The impact of health education based on PRECEDE model on knowledge, attitude and behavior of grade nine female students about iron deficiency anemia in Qazvin. Journal of Health 2016;7(3):321-30.

[28] Hazavehei SMM, Pirzadeh A, Entezari MH, et al. The effect of educational program based on BASNEF model on the nutritional behavior of students. Zahedan Journal of Research in Medical Sciences 2011;13(1):23-9.

[29] Amani R, Soflaei M. Nutrition education alone improves dietary practices but not hematologic indices of adolescent girls in Iran. Food and Nutrition Bulletin 2006;27(3):260-4.

[30] Chiang LC, Huang JL, Lu CM. Educational diagnosis of self-management behaviors of parents with asthmatic children by triangulation based on PRECEDEPROCEED model in Taiwan. Patient Education and Counseling 2003;49(1):19-25.

[31] Baga IR, Mashoofi M, Hosseini MM, et al. The effect of education on knowledge, attitude \& practice of midschool girls on iron-deficiency anemia in Khalkhal in 2009. J Health 2010;1(3):57-66.

[32] Lippin TM, Eckman A, Calkin KR, et al. Empowerment-based health and safety training: evidence of workplace change from four industrial sectors. American Journal of Industrial Medicine 2000;38(6):697-706. 
[33] Peyman N, Charoghchian KE, Moghzi M. The impact of education on the basis of the theory of planned behavior on junk food consumption in high school in Chenaran. Razi J of Med Sci 2016;23(149):62-72.

[34] Pawlak R, Connell C, Brown D, et al. Predictors of multivitamin supplement use among AfricanAmerican female students: a prospective study utilizing the theory of planned behavior. Ethnicity and Disease 2005;15(4):540-7.

[35] Tabatabaei AS, Taghdisi M, Nakheei N, et al. effect of educational intervention based on the theory of planned behaviour on the physical activities of Kerman Health Center's Staff (2008). JBUMS 2010;12(2):62-9.

[36] Mohammadimanesh A, Rakhshani F, Eivazi R, et al. Effectiveness of educational intervention based on theory of planned behavior for increasing breakfast consumption among high school students in Hamadan. J Educ Community Health 2015;2(2):56-65.

[37] Zendehtalab HR. The effect of intervention based on the theory of planned behavior on improving nutritional behaviors of students. J Research Health 2014;4(4):903-10.
[38] Mehrabian F, Valipour R, Kasmaei P, et al. The effect of education based on BASNEF model on promoting of nutritional behavior to prevent iron deficiency anemia. Journal of Holistic Nursing and Midwifery 2016;26(1):89-98.

[39] Conner M, Kirk SF, Cade JE, et al. Why do women use dietary supplements? The use of the theory of planned behavior to explore beliefs about their use. Social Science \& Medicine 2001;52(4):621-33.

[40] Sun WY, Sangweni B, Chen J, et al. Effects of a community-based nutrition education program on the dietary behavior of Chinese-American college students. Health Promotion International 1999;14(3):241-50.

[41] Amiri P. Designation and evaluation for educational program in order to decrease iron-deficiency anemia among adolescent girls [Thesis]. Tehran: Tarbiat Modarres University, 2001.

[42] Hosseiny M. Survey knowledge, attitude and practice girl's students about iron deficiency anemia. Journal of Medical Science University Gorgan 2006;8(3):37-43.

[43] Dehdari T, Khezeli M, Bakhtiyari M, et al. Health education interventions on student nutrition: a systematic review. J Health \& Hygiene 2012;3(3):6272. 